\title{
Molecular Reactivity of Busulfan \\ Through Its Experimental \\ Electrostatic Properties in the Solid State
}

\author{
Nour Eddine Ghermani, ${ }^{1,2,4}$ Anne Spasojevic'-de Bire', ${ }^{2}$ \\ Nouzha Bouhmaida, ${ }^{2,3}$ Souad Ouharzoune,,${ }^{1,2}$ Je'rôme Bouligand, ${ }^{1}$ Anne Layre, ${ }^{1}$ Ruxandra Gref, ${ }^{1}$ and Patrick \\ Couvreur $^{1}$
}

\begin{abstract}
Purpose. In the route of developing novel liquid phase formulations based on the encapsulation of busulfan into liposomes in nontoxic solvents, drug crystallization inevitably occurs. In order to better understand the reactivity of busulfan, the characterization of its molecular properties was therefore considered as a key point. Also, preliminary attempts to prevent crystallization using cyclodextrins were explored.

Methods. An accurate single-crystal high-resolution X-ray diffraction experiment at $100 \mathrm{~K}$ has been carried out. The experimental electron density of busulfan was refined using a multipole model. Busulfan/ -cyclodextrin coprecipitates were analyzed by powder X-ray diffraction and ${ }^{1} \mathrm{H}-\mathrm{NMR}$ spectroscopy.

Results. The electrostatic properties of busulfan and the methylsulfonate fragment dipole moment (3.2 D) were determined. The polar moieties play a key role in the crystallization of busulfan, which presents a nucleophilic region surrounding the sulfonate part, whereas the carbon chain displays an electrophilic character. This highlights the subtle busulfan/-cyclodextrin association.

Conclusions. Busulfan electrostatic properties were used to quantify its chemical reactivity. This explains the difficulty to formulate busulfan into liposomes due to a strong polar character of the methylsulfonate terminal groups. The complexation with cyclodextrins deserves to be further investigated to allow the formulation of busulfan in nontoxic solvents.
\end{abstract}

KEY WORDS: busulfan; busulfan-cyclodextrin complex; electron density; high-resolution crystallography.

\section{INTRODUCTION}

The formulation of molecules with a trend to crystallize is a major problem in pharmacy, not only because the shape and overall dimensions of the obtained crystals have an important impact in the mechanical manufacturing of solid dosage forms (storage, flow, compression, tabletting, and so forth), but also because it may impact the release profile of

\footnotetext{
Laboratoire Physico-Chimie, Pharmacotechnie, Biopharmacie (PPB) UMR CNRS 8612, Faculte’ de Pharmacie, Universite’ Paris XI, 92296 Cha^tenayMalabry Cedex, France. 2

Laboratoire Structures, Proprie'te's et Mode'lisation des Solides (SPMS) UMR CNRS 8580, Ecole Centrale Paris, 92295 Cha^tenayMalabry Cedex, France. 3

Laboratoire des Sciences des Mate'riaux (LSM), Faculte' des Sciences Semlalia, Universite' Cadi Ayyad, BP 2390, 40000 Marrakech, Morocco. 4

To whom correspondence should be addressed. (e-mail: noureddine.

ghermani@cep.u-psud.fr)
}

the drug. Additionally, the design of liquid pharmaceutical formulations with crystallizable molecules is still more problematic, especially when the drug concentration is close to the limit of solubility. Another concern is the risk of the crystallization of drugs in vivo after administration, as it is the case with busulfan (1,4-butanediol-dimethylsulfonate), a powerful antitumoral agent in leukemias (1). Typically, one of the main side effects observed clinically for therapies with a high dose rate of busulfan is the hepatic veno-occlusive complication due to the microcrystallization of this drug in the microvenous system of the liver (2-4). These considerations have promoted the search for more appropriate and effective formulations of busulfan among which liposomes have been proposed and tested in phase I/II clinical trials (5). However, although these formulations were not satisfyingly characterized, it is likely that in the conditions used for the preparation of the liposomes, busulfan should crystallize outside the vectors. In general, there is a lack of understanding the drug properties at the atomic level to guide the formulation in order to find new strategies to prevent the crystallization. In the current study, using busulfan as a drug model, we have carried out a high-resolution X-ray diffraction experiment at $100 \mathrm{~K}$ to characterize the electron density and electrostatic properties of this drug in the solid state. Crystal structures of busulfan and related molecules $\left[\mathrm{CH}_{3}-\mathrm{SO}_{2}-\right.$ $\mathrm{O}\left(\mathrm{CH}_{2}\right)_{\mathrm{n}} \mathrm{O}-\mathrm{SO}_{2}-\mathrm{CH}_{3}, \mathrm{n}$ 2, 3, 4] were first reported by MacKenna et al. (6) from room-temperature experiments. The authors focused on the molecular conformations with respect to the DNA crosslinking potential. In our work, we try to go further in the investigation of busulfan electronic properties. First, the characterization of the molecular bond electron density through topological analysis using the "Atoms in Molecules" theory (7) clearly demonstrated the alkylating power of busulfan in relation to the cross-linking of DNA strands. Afterwards, the electrostatic potential and the methylsulfonate fragment dipole moment were quantified experimentally. These two properties are fundamental to highlight the reactivity of the busulfan and to better understand the self-affinity of molecules giving rise to the observed strong crystallization.

Finally, in the search of an alternative way to stop the crystallization of busulfan in nontoxic solvents for further formulations, we considered the use of cyclodextrins. These molecules are able to form inclusion complexes with drugs, enhancing their stability and 
solubility in water $(8,9)$. The second part of this study concerns the characterization of the busulfan/-cyclodextrin-associated systems by powder X-ray diffraction and ${ }^{1} \mathrm{H}-\mathrm{NMR}$ spectroscopy. Correlations with the molecular electrostatic properties were established.

\section{MATERIALS AND METHODS}

\section{Materials}

Crystallization of Busulfan

Crystalline white powder of busulfan was purchased from Sigma-Aldrich (Schnelldorf, Germany). Busulfan is soluble in numerous common organic solvents but weakly in pure water. Crystals are easily obtained in few hours by slow evaporation at room temperature. The addition of water, polymers, or other molecules in different $\mathrm{v} / \mathrm{v}$ ratios with busulfan in cosolvent solutions did not affect the crystallization of the drug (10). However, no crystals of busulfan were obtained in more polar solvents like dimethylsulfoxide (DMSO) or dimethylacetamide (DMAC) in normal conditions of supersaturated solution evaporation. The crystals of busulfan are of very good quality, colorless, and have a shape of prisms or elongated blocks. The crystal of busulfan used in this study was obtained from a solution

of ethanol.

Preparation of Busulfan-Cyclodextrin Systems

Crystalline powder of native -cyclodextrin hydrate was purchased from Roquette Frères (Lestrem, France). Thirty milliliters of acetone unsaturated solution of busulfan $(0.16$ and $0.08 \mathrm{~g}$ for $1: 1$ and 1:2 molar ratios) was added to $50 \mathrm{ml}$ of aqueous solution of cyclodextrin $(0.75 \mathrm{~g})$. The limpid solutions were stirred for 5 days at room temperature. In a slow kinetic process, a precipitation progressively appeared in the glass beakers. The solutions were then filtered, and the solid coprecipitates (white powders) were air-dried during $24 \mathrm{~h}$ and first analyzed by X-ray powder diffractometry. Afterwards, the busulfan--cyclodextrin coprecipitates were dissolved in deuterated water $\left(\mathrm{D}_{2} \mathrm{O}\right)$ for a ${ }^{1} \mathrm{H}-\mathrm{NMR}$ spectroscopy analysis.

\section{Methods}

Single-Crystal X-Ray Data Collection

The single-crystal X-ray high-resolution data collection was performed at $100 \mathrm{~K}$ on a Bruker-Smart 3-circle (, , ) diffractometer (Karsrhue, Germany) equipped with a CCDship area detector. The X-ray beam corresponds to the Mo K radiation ( $0.71073 \AA$ ). The high resolution reached was $d 0.408 \AA\left(1 \AA 10^{-10} \mathrm{~m}\right)$ corresponding to $(\sin /)_{\max } 1.225 \AA^{-1}$. The collected frames were recorded with a scan interval of $0.15^{\circ}$. The SAINT program (11) of the Smart software package was used to correct data from the Lorentz and polarization phenomena and to integrate the peak diffraction intensities. In the experiment, 46,878 reflections were collected, yielding 5421 unique data having intensities I > 3(I) used as observations in the electron density refinements. The standard deviations (I) were estimated from the variance analysis performed during the averaging of the equivalent reflection intensities (12). Table I summarizes the experimental details.

\section{$X$-Ray Powder Diffractometry and ${ }^{1} H$-NMR Spectroscopy}

X-ray diffraction lines of the busulfan--cyclodextrin hydrate and the coprecipitates of busulfan--cyclodextrin (molar ratios 1:1 and 1:2) were recorded at room temperature on a Siemens D5000 diffractometer (Karsrhue, Germany) using Cu K radiation ( $1.54051 \AA$, 40 $\mathrm{kV}$, and $35 \mathrm{~mA}$ ) in

Bragg-Brentano reflection geometry. The powder diffraction patterns correspond to a 2 angle scan range from $3^{\circ}$ to $70^{\circ}$ with a $0.02^{\circ}$ step size and $1 \mathrm{~s} /$ step. The diffractograms were visualized using the WINPLOTR program of the FULLPROF package (13). ${ }^{1} \mathrm{H}-\mathrm{NMR}$ resonances of the busulfan, -cyclodextrin, and busulfan--cyclodextrin systems were recorded on a Bruker DRX 400-MHz spectrometer (Wissenbourg,

France).

Table I. Single-Crystal Experiment and Refinement Details

\begin{tabular}{ll}
\hline Chemical formula & $\mathrm{C}_{6} \mathrm{H}_{14} \mathrm{O}_{6} \mathrm{~S}_{2}$ \\
Formula weight $\left(\mathrm{g} \mathrm{mol}^{-1}\right)$ & 246.3 \\
Temperature $(\mathrm{K})$ & $100.0(1)$ \\
Wavelength $(\AA)$ & 0.71073 \\
Crystal system & Triclinic \\
Space group & \\
& - \\
$\mathrm{a}(\AA)$ & $\mathrm{P} 1$ \\
$\mathrm{~b}(\AA)$ & $5.5246(1)$ \\
$\mathrm{c}(\AA)$ & $6.7386(1)$ \\
& $7.4728(1)$
\end{tabular}




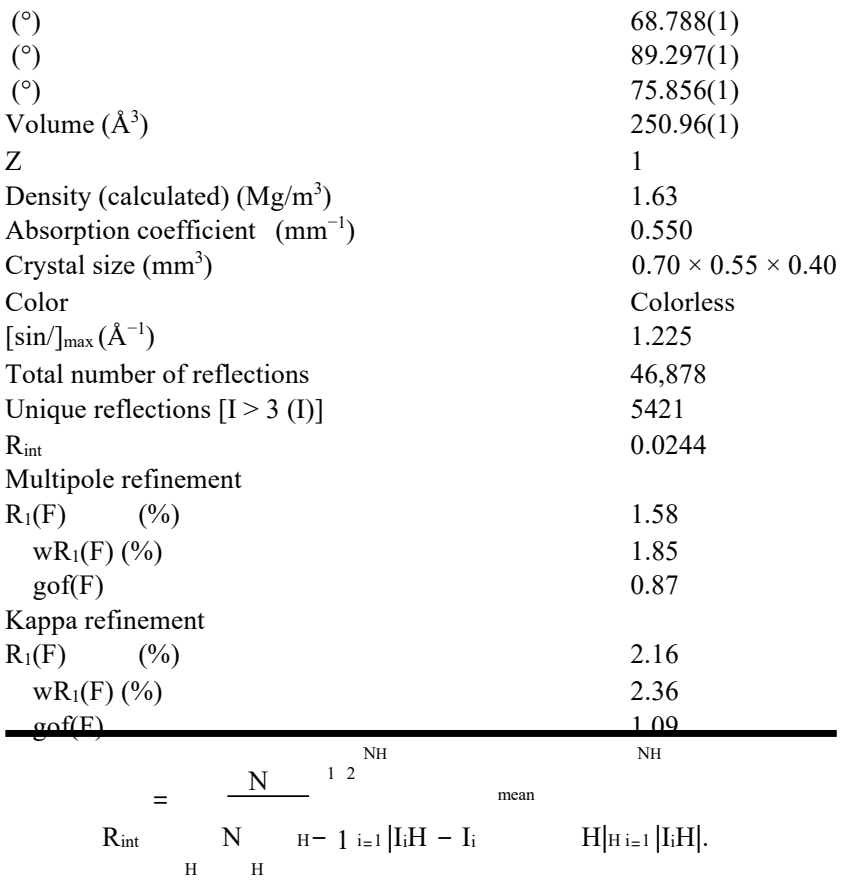

$\mathrm{I}(\mathrm{H})$ is the observed reflection intensity at the Bragg vector $\mathrm{H} . \mathrm{N}_{\mathrm{H}}$ is the number of equivalent and redundant reflections.

$$
\begin{aligned}
\mathrm{R}_{1} & =\| \mathrm{F}_{\text {obs }}|-| \mathrm{F}_{\text {calc }}||\left|\mathrm{F}_{\text {obs }}\right|=\left[\sum \mathrm{wF}_{\text {obs }}-\mathrm{F}_{\text {calc2 } 2 \mathrm{~W}_{\text {obs2 } 2} \text { 12wR1 }}\right. \\
& =\mathrm{w}\left|\mathrm{F}_{\text {obs }}\right|-\left|\mathrm{F}_{\text {calc }}\right| 2 \mathrm{~m}_{\text {obs }}-\mathrm{n}_{\mathrm{p} 12 .} .
\end{aligned}
$$

$\mathrm{F}_{\mathrm{obs}}$ and $\mathrm{F}_{\text {calc }}$ are the observed and calculated structure factors, respectively. The statistical weight is $\mathrm{w} 1 /^{2}\left(\mathrm{~F}_{\mathrm{obs}}{ }^{2}\right) \mathrm{g}$ of $(\mathrm{F})$, where ${ }^{2}$ is the variance and mobs and $n_{p}$ are the number of observations and refined parameters, respectively.

\section{Structure and Electron Density Refinements}

The crystal structure was solved by direct methods (14) and first refined with the SHELXL-97 program of the WINGX software package (15). The obtained parameters were then transferred to the input files of the MOLLY program (16) based on the Hansen-Coppens electron density model, where the total electron density model $(r)$ of the molecule is calculated as the sum of atomic contributions

$$
\begin{aligned}
& \underset{1 \max }{{ }_{a t}}(\mathbf{r})=\quad{ }_{1}^{\operatorname{core}(r)}+\mathrm{P}_{\text {val } 3} \quad \text { val } \mathrm{r} \\
& { }^{3} \mathrm{R}_{1} \mathrm{r} \underset{\mathrm{m}=0}{\mathrm{P}=0} \mathrm{P}_{\operatorname{lm} \pm} \mathrm{y}_{\operatorname{lm} \pm},
\end{aligned}
$$

In Eq. (1), core and val are Hartree-Fock free atomic core and valence spherical electron densities (17), respectively. The third part in Eq. (1) is the aspherical atomic electron density described by the real spherical harmonic angular functions $\mathrm{y}_{l \mathrm{~m} \pm}($,$) and modulated$ by a radial Slater-type function

$$
\mathrm{n} 1+3
$$

$$
\mathrm{R}_{1} \mathrm{r}=\overline{\mathrm{n}+2 !} \mathrm{r}_{\mathrm{n} 1 \mathrm{e}}-1 \mathrm{r}
$$

The least-squares fitted parameters are the valence population $P_{v a l}$ yielding the atomic charge $\left(q P_{v a l}-N_{v a l}\right.$; $N_{v a l}$ is the valence population of a free atom) and the multipole populations $\mathrm{P}_{l_{\mathrm{m}} \pm}$ characterizing the electron deformation density. The contraction (, $\left.>1\right)$ or expansion $(,<1)$ coefficients of the atomic electron density are also refined.

In this study, the chosen radial function arguments in Eq. (2) were $3.95,4.50,3.00$, and 2.26 bohr $^{-1}$ (1 bohr $0.52918 \AA$ ) for S, O, C, and $\mathrm{H}$, respectively (18). The best refinement results were obtained for exponents $n_{1} 3,3,4,4$ (up to hexadecapole level) for $S$, $n_{1} 2,2,3$ (up to octupole level) 


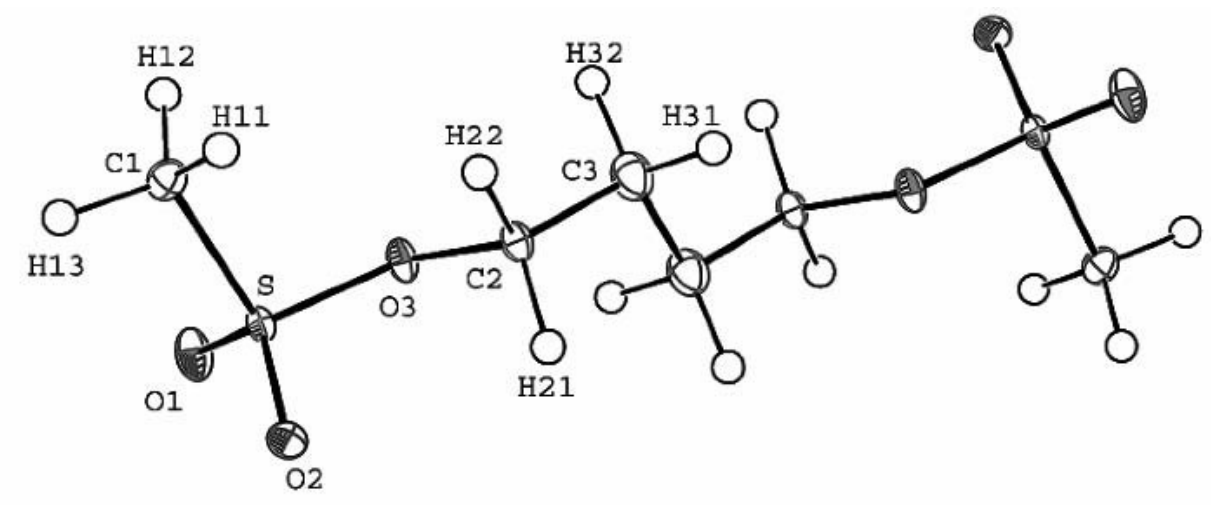

(a)
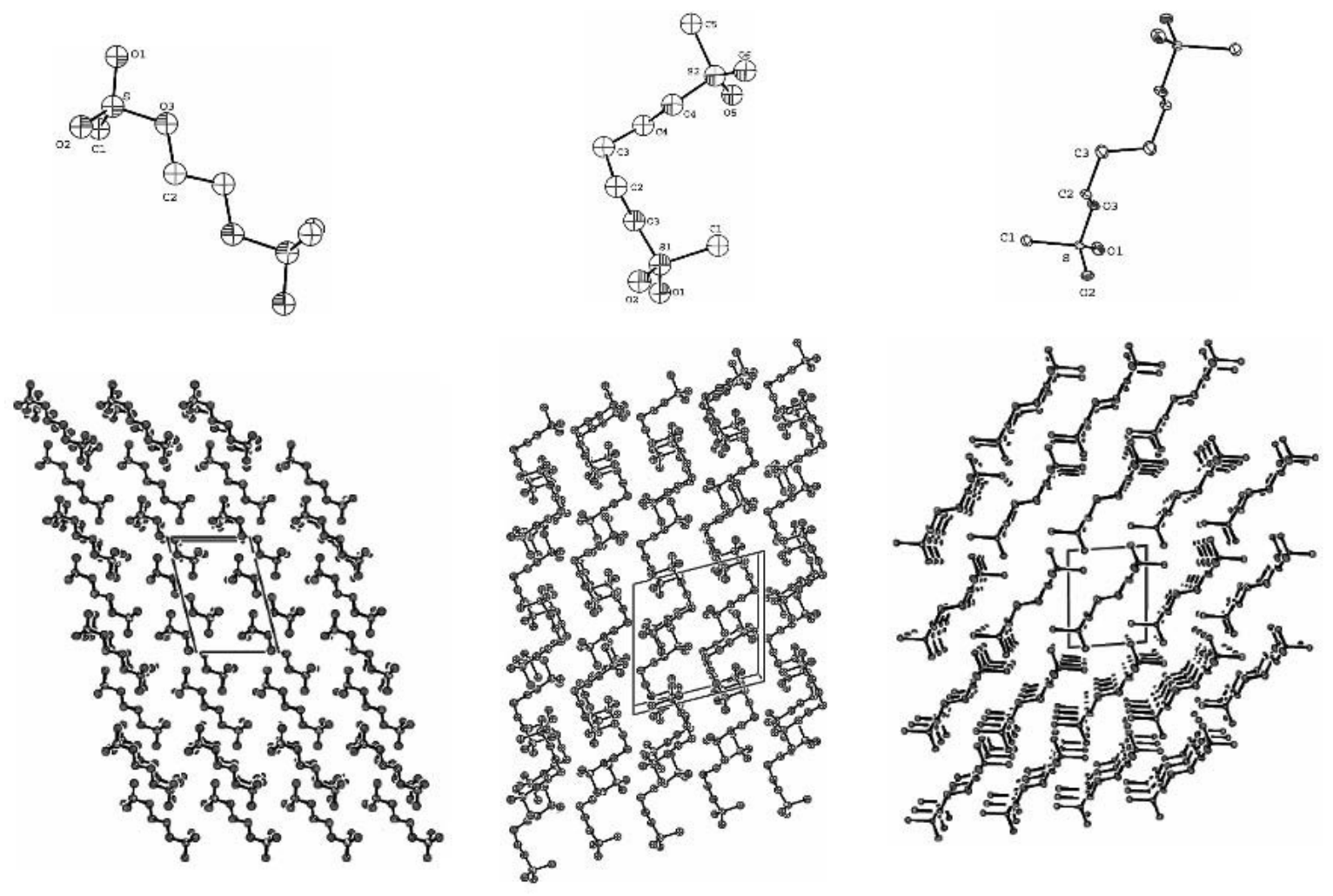
Fig. 1. (a) ORTEP diagram of the busulfan molecule with $50 \%$ probability thermal ellipsoids. (b) View of the busulfan $\mathrm{CH}_{3}-\mathrm{SO}_{2}-\mathrm{O}\left(\mathrm{CH}_{2}\right)_{n} \mathrm{O}-$ $\mathrm{SO}_{2}-\mathrm{CH}_{3}$ analogs [n 2, 3 from MacKenna et al. (6) and n 4 from this study] crystal packing perpendicular to b crystallographic axis. Hydrogen atoms are omitted for clarity.

for $\mathrm{C}$ and $\mathrm{O}$, and $\mathrm{n}_{1} 1$ (up to dipole level) for $\mathrm{H}$. Charge and dipole parameter constraints were imposed to chemically equivalent hydrogen atoms. After the multipole refinements, the atomic net charges were estimated through a kappa refinement (19) based on the spherical part in Eq. (1). Figure 1a shows the ORTEP diagram (20) displaying the atomic thermal vibrations of the busulfan molecule. The refinement statistical factors are given in Table I. 
STATDENS program (21) was used to calculate and plot the electron deformation density as def $\quad$ model- free where free is the superposition of the free atom model electron densities. To gain further insight into the atomic bond properties, the "Atoms in Molecules" theory developed by Bader (7) establishes a direct relation between the total electron density distribution of a chemical system and the energetic properties of the bonds. The topological analysis was performed through the gradient (r) and the Laplacian $^{2} \quad(\mathbf{r})$ of the electron density. The zeroes of $\quad(\mathbf{r})$ localize the extrema at $\mathbf{r}_{\mathrm{c}}$ called bond critical points (BCPs). ${ }^{2}$ (r) is also related to the potential (r) (negative) and kinetic G(r) (positive) energy densities

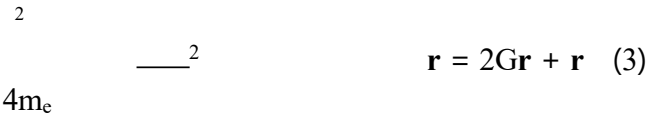

Therefore, $^{2} \quad\left(\mathbf{r}_{\mathrm{c}}\right)<0$ indicates a concentration of electrons at $\mathbf{r}_{\mathrm{c}}\left[\left(\mathbf{r}_{\mathrm{c}}\right)\right.$ dominates $]$ and ${ }^{2} \quad\left(\mathbf{r}_{\mathrm{c}}\right)>0$ corresponds to a depletion of electrons at $\mathbf{r}_{\mathrm{c}}\left[\mathrm{G}\left(\mathbf{r}_{\mathrm{c}}\right)\right.$ dominates]. The NEWPROP (22) program was used to analyze the topological features of the experimental electron density of the busulfan. The bond energy density $H \mathrm{G}\left(\mathbf{r}_{\mathrm{c}}\right)+\left(\mathbf{r}_{\mathrm{c}}\right)$ can also be quantified from the values of ${ }^{2}\left(\mathbf{r}_{\mathrm{c}}\right)$ [Eq. (3)] at $\mathbf{r}_{\mathrm{c}}$ using the empirical formula of the kinetic energy density (23)

$$
\frac{3}{10} \quad-\overline{G r}_{\mathrm{c}}=3^{\overline{2}}{ }_{3253} \mathbf{r}_{\mathrm{c}}+12 \quad \mathbf{r}_{\mathrm{c}} \text { (4) }
$$

6

\section{Electrostatic Properties}

The molecular electrostatic potential V(r) was calculated using the ELECTROS program (21) as molecule

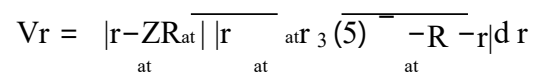

the sum of the contributions of the positive nuclear charge $Z_{a t}$ and the electron density at of the pseudoatom at $\mathbf{R}_{\text {at }}$ [Eq. (1)]. We also have used the electrostatic potential to derive the dipole moment of the methylsulfonate fragment of the busulfan molecule (24).

\section{RESULTS AND DISCUSSION}

\section{Molecular Conformation and Crystal Packing}

The busulfan crystallizes in P1 triclinic space group with one molecule in the unit cell. Figure 1a shows the crystal conformation of the busulfan molecule where the inversion center is in the middle of the $C_{3}-C_{3}$ bond. The bond lengths and angles obtained after the multipole refinement are in good agreement with those reported in the previous study (6). The sulfur atom of the terminal methylsulfonate $\left(\mathrm{CH}_{3} \mathrm{SO}_{3}\right)$ fragment is in a distorted tetrahedral coordination with two short SO bond distances for $\mathrm{SO}_{1}$ and $\mathrm{SO}_{2}$ [1.4276(3) and 1.4097(3) $\AA$, respectively]. Consequently, the oxygen electron repulsion in the $\mathrm{SO}_{2}$ part of the methylsulfonate fragment widens the $\mathrm{O}_{1}-\mathrm{S}-\mathrm{O}_{2}$ bond angle $\left[119.39(3)^{\circ}\right]$. In contrast, $\mathrm{O}_{3}$ is singly bonded to $\mathrm{S}\left[\mathrm{S}-\mathrm{O}_{3} 1.5847(2) \AA\right]$ and to $\mathrm{C}_{2}\left[\mathrm{C}_{2}-\mathrm{O}_{3} 1.4671(4) \AA\right]$. $\mathrm{C}_{1}$ methyl carbon is at 1.7354(3) $\AA$ from S. All these SO, S-O, S-C, and C-O bond distance values are in relatively good agreement with the average estimates retrieved from the Cambridge Structural Data Center (CSDC) (25) for similar fragments: $<\mathrm{SO}>1.412,<\mathrm{S}-\mathrm{O}>1.571,<\mathrm{S}-\mathrm{C}>1.732$, and $<\mathrm{C}-\mathrm{O}>1.462 \AA$, respectively. In the carbon chain of busulfan, the $\mathrm{C}_{2}-\mathrm{C}_{3}$ bond length (1.5253(4) $\AA$ ) is similar to that of the central $\mathrm{C}_{3}-\mathrm{C}_{3}$ link [1.5291(5) $\AA$ ]. The gauche-, trans, gauche- crystal conformation (6) maintains the two $\mathrm{O}_{3}$ ester oxygen atoms at a distance of $5.1956(5) \AA$. On the other hand, Fig. 1b compares the crystal packing of busulfan analogs

$\left[\mathrm{CH}_{3}-\mathrm{SO}_{2}-\mathrm{O}\left(\mathrm{CH}_{2}\right)_{\mathrm{n}} \mathrm{O}-\mathrm{SO}_{2}-\mathrm{CH}_{3}, \mathrm{n} 2,3,4\right]$. It is worth noting that the crystal packing looks very similar for $\mathrm{n} 2$ and 4 for which the molecules are stretched, whereas for $\mathrm{n} 3$, the central carbon permits the molecule to be bent. Given the nature of these molecules, only weak intermolecular $\mathrm{O} \cdots \mathrm{H}(\mathrm{C})$ interactions are observed $(>2.37 \AA)$. Therefore, the crystal packing of these three molecules mainly originates from electrostatic and van der Waals interactions, particularly those involving the methylsulfonate fragment with a pronounced

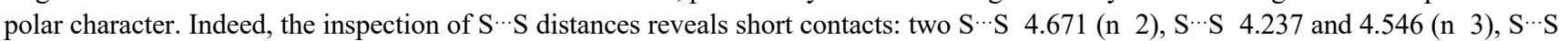
4.119 (n 4 at room temperature) and 4.0729(1) $\AA$ (n 4 at $100 \mathrm{~K}$ ), respectively. This latter emphasizes that the methylsulfonate fragment interactions are enhanced in the busulfan crystal lattice. Furthermore, the intermolecular torsion angles for the closest pairs of methylsulfonate fragments are $\mathrm{C}-\mathrm{S} \cdots \mathrm{S}-\mathrm{C} 48.2^{\circ}$ (for the two $\mathrm{S} \cdots \mathrm{S}$ contacts for $\mathrm{n} 2$ ), $180.0^{\circ}$ (n 3), and $180.0^{\circ}$ for the busulfan (n 4). Except for $\mathrm{n}$ 2, the $\mathrm{C}-\mathrm{S}$ axes of the methylsulfonate fragments are antiparallel in order to minimize the dipole-dipole interactions.

\section{Electron Deformation Density}

The static electron deformation density in the chemical bonds of busulfan is depicted in Fig. 2. Figure 2a shows the electron density distribution in $\mathrm{O}_{1} \mathrm{SO}_{2}$ part of the methylsufonate fragment. Electron density peak heights of $0.70 \mathrm{e}^{-3}$ and $0.55 \mathrm{e} \AA^{-3}$ are found for $\mathrm{SO}_{1}$ and $\mathrm{SO}_{2}$ bonds, respectively. Figure $2 \mathrm{a}$ also shows that the oxygen lone pairs are not symmetric. On the contrary, theoretical calculations on the isolated $\mathrm{H}_{3} \mathrm{NSO}_{3}$ molecule show symmetrical density in the $\mathrm{SO}$ bond and the lone pairs (26). In the $\mathrm{C}_{1}-\mathrm{S}-\mathrm{O}_{3}$ plane of Fig. $2 \mathrm{~b}$, the 
electron density peak heights are 0.50 e $\AA^{-3}$ in both $\mathrm{S}-\mathrm{O}_{3}$ and $\mathrm{S}-\mathrm{C}_{1}$ bonds. Figure $2 \mathrm{c}$ gives a global view of the electron deformation density in the busulfan. The inversion center connecting $\mathrm{C}_{3}$ to $\mathrm{C}_{3}$ ' carbon atoms (with electron density peak height of $0.35 \mathrm{e}^{-3}$ ) is in the middle of the map in Fig. $2 \mathrm{c}$.

\section{Bond Topological Properties}

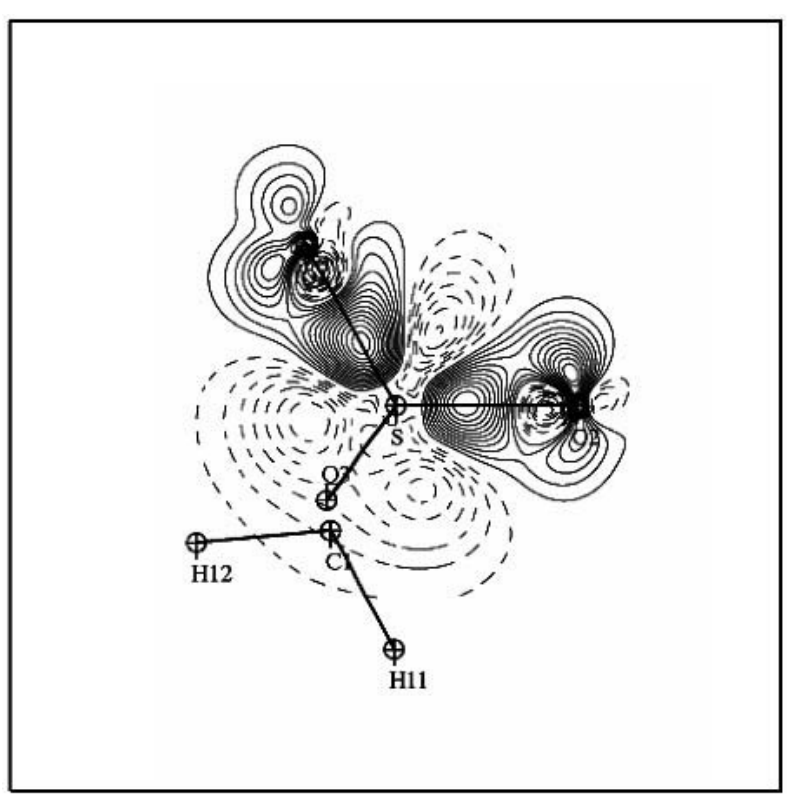

(a)

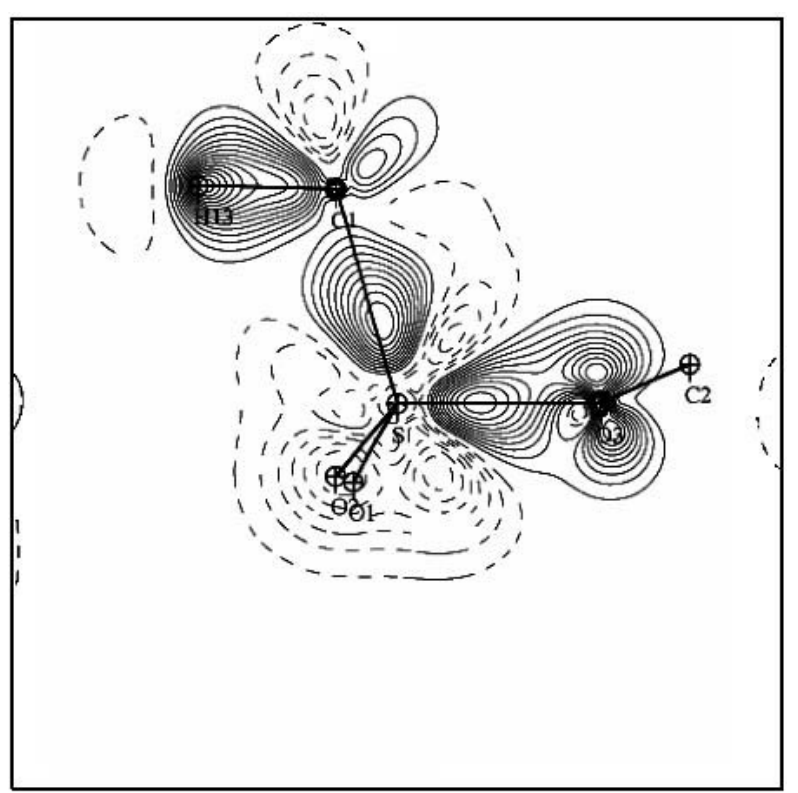

(b)

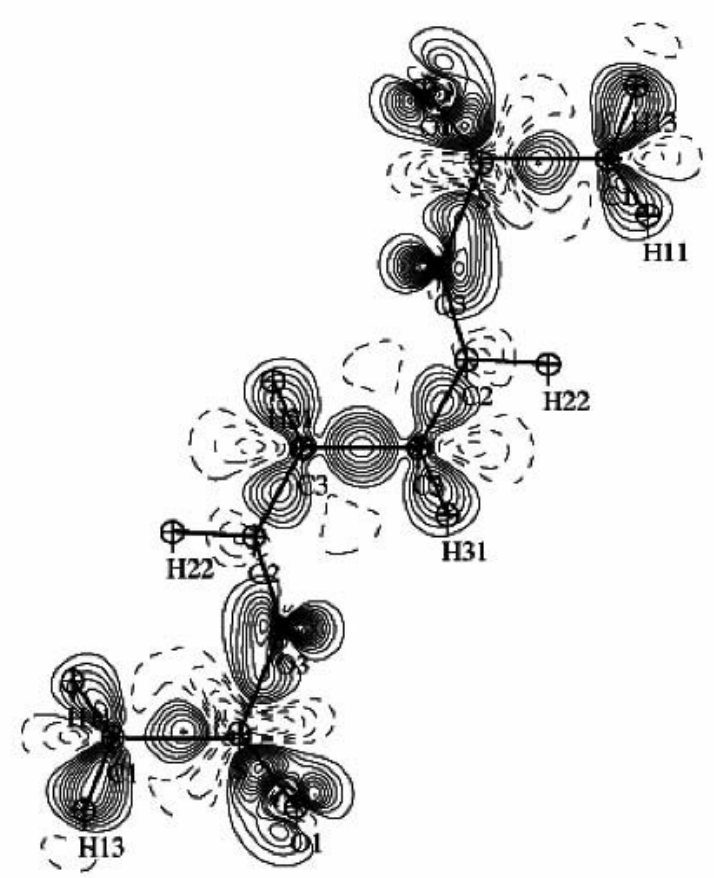

(c) 
Fig. 2. Static electron deformation density maps: (a) $\mathrm{O}_{1}-\mathrm{S}-\mathrm{O}_{2}$; (b) $\mathrm{C}_{1}-\mathrm{S}-\mathrm{O}_{3}$; (c) global view centered on $\mathrm{C}_{3}-\mathrm{C}_{3}$ bond. Contours interval is \pm 0.05 $\mathrm{e} \AA^{-3}$; negative contours are dashed; zero contour omitted.

Table II lists the topological descriptors of the busulfan atomic bonds. All ${ }^{2} \quad$ values have a negative sign at the bond critical points (BCPs). This means from Eq. (3) that the bonds in busulfan have a covalent character (shared shell interactions) where the potential energy dominates. In the methylsulfonate fragment of busulfan, the double bond character of $\mathrm{SO}_{1}$ and $\mathrm{SO}_{2}$ is clearly revealed by large values of at $\mathrm{BCP}\left(2.52\right.$ and $\left.2.43 \mathrm{e}^{-3}\right),{ }^{2} \quad\left(-21.97\right.$ and $\left.-16.53 \mathrm{e} \AA^{-5}\right)$ compared to those of the single bond $\mathrm{S}-\mathrm{O}_{3}($ $\left.\mathrm{e} \AA^{-3},^{2}-13.72 \mathrm{e} \AA^{-5}\right)$. A much lower electron density is found in $\mathrm{S}-\mathrm{C}_{1}$ bond $\left(\quad 1.43 \mathrm{e} \AA^{-3}\right)$ with an intermediate magnitude of Laplacian $\left({ }^{2} \quad-8.18 \mathrm{e}^{-5}\right)$. The $\mathrm{C}_{2}-\mathrm{O}_{3}$ bond has the lowest value of the Laplacian $\left({ }^{2} \quad-1.78\right.$ e $\left.\AA^{-5}\right)$ and a $\mathrm{BCP}$ electron density $1.47 \mathrm{e} \AA^{-3}$. In the carbon chain, the topological parameters given in Table II are in good agreement with those reported for organic molecules like peptides (27). On the other hand, the highest moduli of $H$ [Eq. (4)] is found for the SO double bonds (|H| 1656.47 for $\mathrm{SO}_{1}$ and $1521.45 \mathrm{~kJ} \cdot \mathrm{mol}^{-1}$ per atomic unit volume for $\mathrm{SO}_{2}$ ). This is followed by the $\mathrm{C}-\mathrm{H}$ bond energy density modulus in the range of 909.50 to $1032.80 \mathrm{~kJ} \cdot \mathrm{mol}^{-1}$ per atomic unit volume.

However, half of these values are found for $\mathrm{S}-\mathrm{C}_{1}$ and $\mathrm{C}_{2}-\mathrm{O}_{3}$. This latter has the lowest modulus $\left(|H| 609.63 \mathrm{~kJ} \cdot \mathrm{mol}^{-1}\right.$ per atomic unit volume) and then quantifies the alkylating property of the busulfan showing that the $\mathrm{C}_{2}-\mathrm{O}_{3}$ bond can easily be cleaved.

\section{Net Atomic Charges}

The kappa-refinement (19) was carried out in order to estimate the net atomic charges (Table III) in e units (1 e $\left.1.60210^{-19} \mathrm{C}\right)$. Except for hydrogen atoms that are highly

Table II. Topological Properties at the Bond Critical Points (BCPs) of Busulfan*

\begin{tabular}{lccrrr}
\hline Bond & $\mathrm{d}_{1}$ & $\mathrm{~d}_{2}$ & \multicolumn{2}{c}{2} & \\
\hline & & & & & $H$ \\
\hline $\mathrm{SO}_{2}$ & 0.662 & 0.768 & -21.97 & 2.52 & -1656.47 \\
$\mathrm{SO}_{2}$ & 0.641 & 0.770 & -16.53 & 2.43 & -1521.45 \\
$\mathrm{~S}_{-} \mathrm{O}_{3}$ & 0.764 & 0.821 & -13.72 & 1.90 & -1034.58 \\
$\mathrm{C}_{1}-\mathrm{S}$ & 0.731 & 1.005 & -8.18 & 1.43 & -640.97 \\
$\mathrm{C}_{2}-\mathrm{O}_{3}$ & 0.620 & 0.848 & -1.78 & 1.47 & -609.63 \\
$\mathrm{C}_{3}-\mathrm{C}_{2}$ & 0.739 & 0.787 & -11.82 & 1.67 & -841.23 \\
$\mathrm{C}_{3}-\mathrm{C}_{3}$ & 0.765 & 0.765 & -9.94 & 1.53 & -724.52 \\
$\mathrm{H}_{11}-\mathrm{C}_{1}$ & 0.377 & 0.671 & -15.71 & 1.85 & -1013.05 \\
$\mathrm{H}_{12}-\mathrm{C}_{1}$ & 0.384 & 0.667 & -15.28 & 1.81 & -978.00 \\
$\mathrm{H}_{13}-\mathrm{C}_{1}$ & 0.383 & 0.689 & -14.38 & 1.79 & -954.44 \\
$\mathrm{H}_{21}-\mathrm{C}_{2}$ & 0.363 & 0.678 & -17.89 & 1.85 & -1032.80 \\
$\mathrm{H}_{22}-\mathrm{C}_{2}$ & 0.372 & 0.708 & -14.98 & 1.75 & -929.41 \\
$\mathrm{H}_{31}-\mathrm{C}_{3}$ & 0.359 & 0.716 & -15.27 & 1.72 & -909.50 \\
$\mathrm{H}_{32}-\mathrm{C}_{3}$ & 0.360 & 0.701 & -15.65 & 1.73 & -920.43 \\
\hline
\end{tabular}

\footnotetext{
*Laplacian $^{2} \quad$ (in $\mathrm{e}^{-5}$ ); total electron density (in $\mathrm{e} \AA^{-3}$ ); $\mathrm{d}_{1}$ and $\mathrm{d}_{2}$ are the BCP-atom distances (in $\AA$ ). The last column gives the total energy
} density $H$ (in $\mathrm{kJ} \mathrm{mol}^{-1}$ per atomic unit volume).

contracted ( 1.3 to 1.4 ), the kappa parameters for other atoms are very close to 1.0. The sulfur $\left[+0.93(8)\right.$ e] and the methyl carbon $\mathrm{C}_{1}$ $\left[-0.8(1)\right.$ e] atoms carry the highest charges in modulus but with opposite signs. $\mathrm{C}_{1}$ negative charge is compensated by 3 times $+0.28(4) \mathrm{e}$ corresponding to the three attached protons $\mathrm{H}_{11}, \mathrm{H}_{12}$, and $\mathrm{H}_{13}$. The double $\mathrm{SO}$ and single $\mathrm{S}-\mathrm{O}$ bonds are characterized by different charges of the oxygen atoms $\mathrm{O}_{1}, \mathrm{O}_{2}$, and $\mathrm{O}_{3}$, which are $-0.54(5)$,

$-0.44(5)$, and $-0.27(5)$ e, respectively. In the carbon chain, $C_{2}$ is almost neutral $\left[q-0.1(1)\right.$ e], whereas the central $C_{3}$ carries $-0.35(8)$ e. The agreement with Mulliken charges is still confirmed here as the theoretical values, reported for the methylsulfonate -1 anion, are $+1.16,-0.65,-0.67$, and +0.15 e for $\mathrm{S}, \mathrm{O}, \mathrm{C}$, and $\mathrm{H}$, respectively (28). Comparatively, in the busulfan molecule, the methylsulfonate fragment has a global charge of $-0.28 \mathrm{e}$. In consequence, the carbon chain in busulfan is positively charged ( $+0.56 \mathrm{e})$. It is then expected that the removal of the methylsulfonate groups during the alkylating process will liberate a high electrophilic radical.

\section{Electrostatic Potential}

Experimentally fitted multipole parameters and net atomic charges were used to calculate the electrostatic poten-

Table III. Kappa Parameters ( ) and Net Atomic Charges (q) of

\begin{tabular}{lll} 
& & Busulfan \\
\hline $\mathrm{S}$ & & $\mathrm{q}$ \\
$\mathrm{O}_{1}$ & $1.043(6)$ & $+0.93(8)$ \\
$\mathrm{O}_{2}$ & $0.973(4)$ & $-0.54(5)$ \\
$\mathrm{O}_{3}$ & $0.985(4)$ & $-0.44(5)$ \\
$\mathrm{C}_{1}$ & $0.994(4)$ & $-0.27(5)$ \\
$\mathrm{C}_{2}$ & $0.988(8)$ & $-0.8(1)$ \\
& $1.009(9)$ & $-0.1(1)$
\end{tabular}




\begin{tabular}{lll}
$\mathrm{C}_{3}$ & $0.999(8)$ & $-0.35(8)$ \\
$\mathrm{H}_{11} \mathrm{H}_{12} \mathrm{H}_{13}$ & $1.41(5)$ & $+0.28(4)$ \\
$\mathrm{H}_{21} \mathrm{H}_{22}$ & $1.29(4)$ & $+0.14(4)$ \\
$\mathrm{H}_{31} \mathrm{H}_{32}$ & $1.30(4)$ & $+0.21(4)$ \\
\hline
\end{tabular}

Standard deviations are given in parentheses.

tial generated around an isolated busulfan molecule. Figure 3 depicts the electrostatic potential isosurfaces corresponding to $\pm 0.05 \mathrm{e} \AA^{-1}$ $\left(1 \mathrm{e} \AA^{-1} 14.4 \mathrm{~V}\right.$ and energetically $\left.1 \mathrm{e}^{2} \AA^{-1} 332.4 \mathrm{kcal} \cdot \mathrm{mol}^{-1} 1389.4 \mathrm{~kJ} \cdot \mathrm{mol}^{-1}\right)$. The minimum electrostatic potential value of $-0.14 \mathrm{e} \AA^{-1}(-$ $0.18 \mathrm{e} \AA^{-1}$ from kappa refinement) is found in the vicinity of $\mathrm{O}_{1}$ oxygen atom compared to $-0.10 \mathrm{e} \AA^{-1}$ (from the two refinements) for $\mathrm{O}_{2}$. These holes of attractive electrostatic potential for positive species like protons are at a distance shorter than $1.5 \AA$ from the $\mathrm{O}_{1}$ and $\mathrm{O}_{2}$ nuclei. The nucleophilic (negative electrostatic potential) regions, similar from the two refinements, have a kidney shape and surround the $\mathrm{O}_{1}$ and $\mathrm{O}_{2}$ oxygen sites of the methylsulfonate moiety. The negative potential does not extent to $\mathrm{O}_{3}$, which is completely inhibited by the strong electrophilicity (positive electrostatic potential) of the carbon chain and methyl groups of busulfan.

\section{Methylsulfonate Fragment Dipole Moment and Crystallization Impacts}

Figure 3 also shows the polar character of the terminal methylsulfonate fragments of busulfan. Positive and negative barycenters are located on the methyl and $\mathrm{SO}_{3}$ groups, respectively. We used the electrostatic potential to calculate the dipole moment of the methylsulfonate fragment using the method we developed earlier (24). The obtained values are 3.23(3) and 4.69(2) D (1 Debye 3.336 $10^{-30} \mathrm{C} \cdot \mathrm{m}$ ) from the multipole and kappa refinements, respectively. The kappa model slightly overestimates the value of the fragment dipole moment, which is very sensitive to the multipole parameters as pointed out by Abramov et al. (29). Comparatively, the estimated dipole moments of the $\mathrm{H}_{2} \mathrm{O}$ and the DMSO molecules are 2.2 D and $3.96 \mathrm{D}$, respectively $(24,30)$. The high value of the methylsulfonate fragment dipole moment explains the antiparallel interactions and the crystal stacking of busulfan molecules. Also, the noncrystallization in polar DMSO or DMAC solutions can be explained by the competition of the dipole interactions between busulfan-busulfan and busulfan-solvent couples.

\section{Busulfan-Cyclodextrin Systems}

The use of cyclodextrins has been considered to try to obtain an inclusion complex with busulfan. The interior of the cyclodextrin cavity is hydrophobic, whereas the external surface is hydrophilic (9). In the inclusion complexes, both steric and electrostatic considerations must to be taken into account. The inspection of the large extent of the negative electrostatic potential (Fig. 3) suggests the use of the -cyclodextrin with an intermediate cavity diameter $(6 \AA)$ in our preparation of coprecipitates with busulfan. The cyclodextrins have cyclic conformations resembling, to some extent, the crownmolecules. The Structural Cambridge Data Bank contains some crystallographic structures of clathrate complexes in presence of $\mathrm{CH}_{3}-\mathrm{SO}_{2}$ or methylsulfonate fragments (25). The reported structures reveal that the methyl group is more involved in the interaction with the host molecule than the sulfonate part. The complex is stabilized by weak interactions between the oxygen atoms of the host molecule and the methyl groups pointing their protons (electrophilic part) toward the molecular cavity.

Figure 4 shows the powder X-ray diffraction patterns 


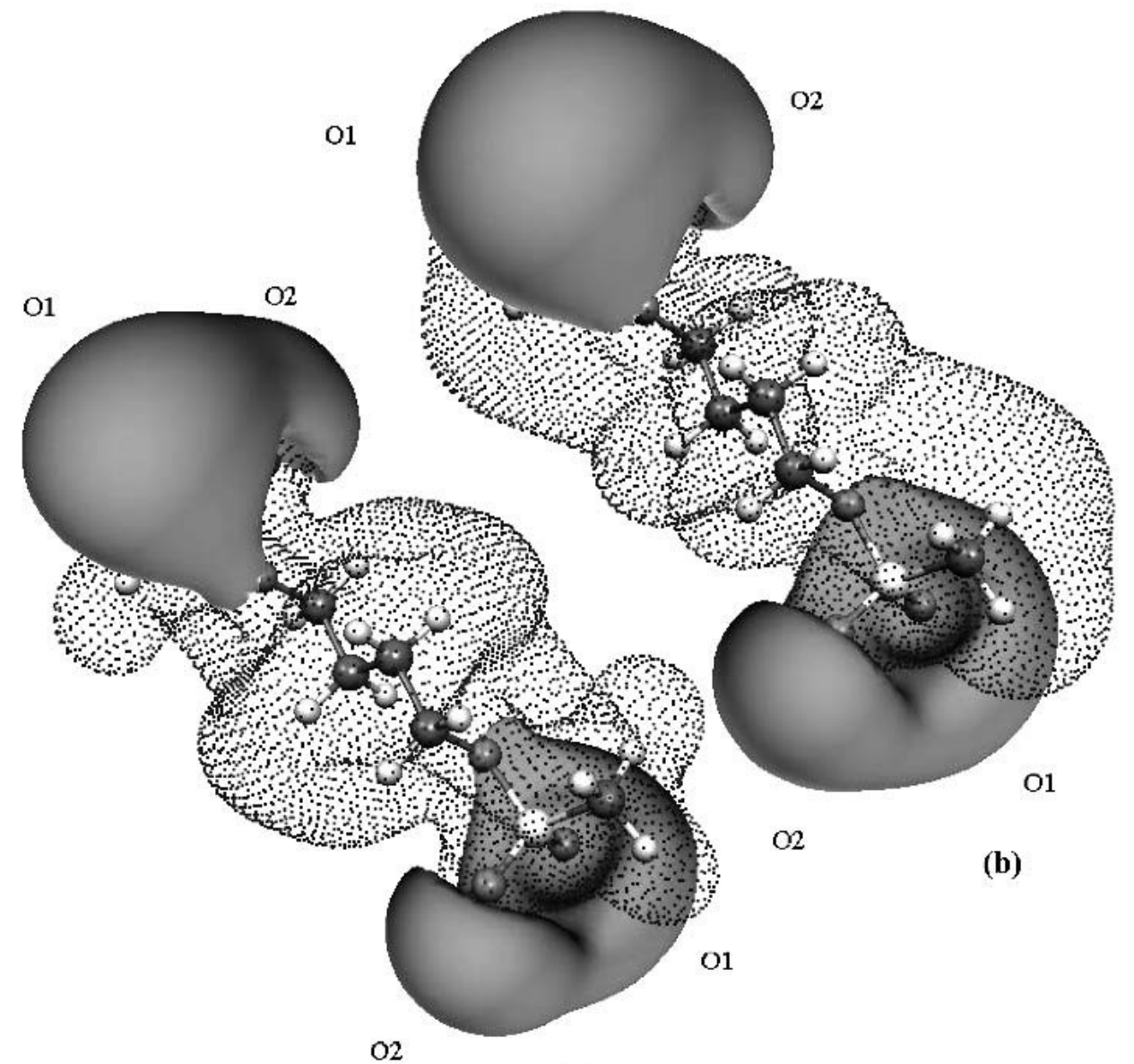

(a)

Fig. 3. Electrostatic potential isosurfaces around the busulfan molecule: (a) from multipole refinement; (b) from kappa refinement. The positive electrostatic potential isosurface $\left(+0.05 \mathrm{e}^{-1}\right)$ is in dots and the negative one $\left(-0.05 \mathrm{e}^{-1}\right)$ is smoothed.

obtained for the different compounds used in this study. Figures $4 \mathrm{a}$ and $4 \mathrm{~b}$ correspond to the starting products of the pure busulfan and cyclodextrin hydrate, respectively. The association in the solid state of the busulfan and -cyclodextrin hydrate with initial 1:1 and 1:2 molar ratios yield crystalline phase compounds with a small part of amorphization characterized by a humped background as shown in Figs. $4 \mathrm{c}$ and $4 \mathrm{~d}$. The view of these patterns suggests two new phases with numerous peaks indicating a quite different behavior of the busulfan-cyclodextrin interactions with respect to the chosen stoichiometries. These new phases are clearly dissimilar from the single physical mixture (not shown here), corresponding to an exact superposition of the patterns in Fig. 4a and 4b. 1:1 and 1:2 busulfan/cyclodextrin diffractograms also differ from that of pure -cyclodextrin hydrate depicted in Fig. 4b. The d-spacing abscissa $(\AA)$ is preferentially used in order to well separate the peaks corresponding to the long-range crystal packing parameters. In the -cyclodextrin hydrate diffractogram, the peaks at d 10.0,14.3, and $20.4 \AA$ can be chosen as reference. The latter value is in good agreement with the highest cell parameter [20.857(6) $\AA]$ determined from a single-crystal study of the -cyclodextrin hydrate (31). Following the three reference peaks, Figs. $4 \mathrm{e}$ and $4 \mathrm{f}$ clearly show differences in the crystal lattice of -cyclodextrin hydrate and those of 1:1 and 1:2 compounds, which suggests that a true association of busulfan and -cyclodextrin exists. This is much more visible for 1:1 compound presenting the most distinguished peak position shifts. However, it is premature at this stage of investigation to identify the type of crystal packing of such solid complexes and the respective arrangements of the host and guest molecules. 1

H-NMR was used to achieve the analysis of the busulfan--cyclodextrin coprecipitates in terms of complexation but also in terms of stability in aqueous medium. The chemical shifts of free -cyclodextrin, pure busulfan, and 1:1 and 1:2 busulfan--cyclodextrin systems are given in Table IV. Owing to the unsolubility of the drug in water, we cannot consider the induced chemical shifts for busulfan. However, in the presence of busulfan in the 1:1 molar ratio system, the $\mathrm{H}_{5}(-0.015 \mathrm{ppm})$ and $\mathrm{H}_{6}(-0.019 \mathrm{ppm})$ protons of the cyclodextrin display the most important induced shifts whereas of $\mathrm{H}_{3}$ is found equal to $-0.005 \mathrm{ppm}$. The upfield shifts of $\mathrm{H}_{5}$ and $\mathrm{H}_{6}$ protons, respectively located on the inner surface and the rim of the cyclodextrin, suggest a shallow position of the busulfan that interacts with the hydroxyl groups of the narrow side of the cavity. This hypothesis can also be supported in light of the observed positive electrostatic potential region surrounding the methyl group and the carbon chain of the busulfan molecule (Fig. 3). The busulfan molecule likely exposes this electrophilic region toward the 

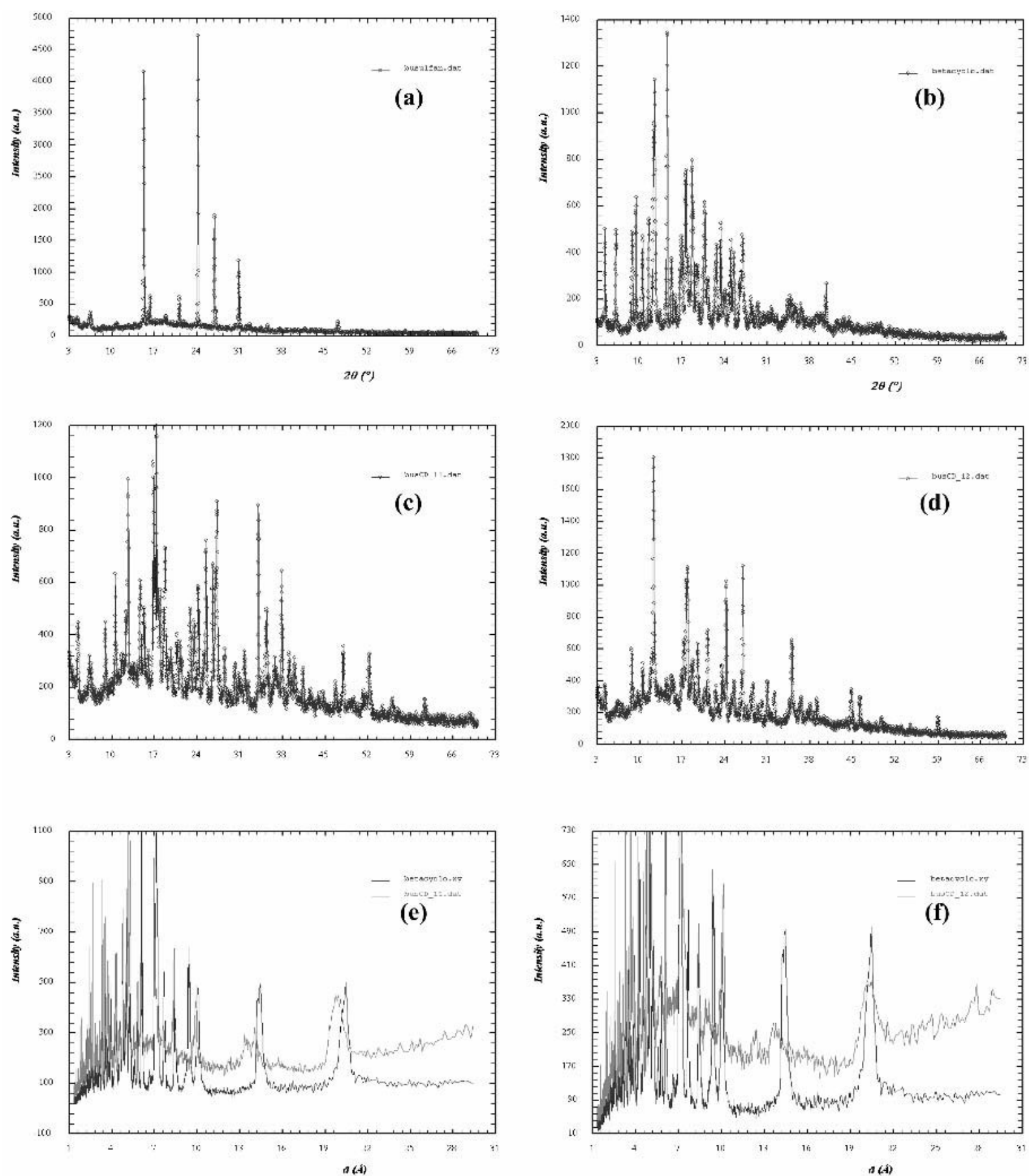

Fig. 4. Powder diffraction patterns: (a) busulfan, (b) -cyclodextrin hydrate, (c) busulfan--cyclodextrin 1:1, (d) busulfan-cyclodextrin 1:2, (e) busulfan--cyclodextrin 1:1 (upper curve) and -cyclodextrin hydrate (lower curve) with d-spacing abscissa ( $\AA$ ), and (f) busulfan--cyclodextrin 1:2 (upper curve) and -cyclodextrin hydrate (lower curve) with d-spacing abscissa ( $\AA$ ). Diffraction intensities are in arbitrary units.

cavity aperture of the cyclodextrin. We note that the crystal conformation of the busulfan depicted in Fig. 1a and the real one in the complex are probably different; the exposed electrophilic part can be extended as consequence of a possible torsion of the carbon chain. On the other hand, no significant shifts are observed for the cyclodextrin protons for the 1:2 coprecipitate in solution. The slight chemical shifts of the cyclodextrin protons in presence of busulfan in the 1:2 system cannot confirm any association in this case. The ${ }^{1} \mathrm{H}-\mathrm{NMR}$ results are thus in good agreement with those observed in the solid state through X-ray powder patterns showing the difference between the $1: 1$ and $1: 2$ systems.

\section{CONCLUSIONS}

This work provides a characterization of the busulfan electrostatic properties derived from an accurate X-ray highresolution diffraction experiment. The chemical bond strengths and the alkylating property of busulfan are quantified through the topological electron density descriptors. The 
Table IV. ${ }^{1} \mathrm{H}-\mathrm{NMR}$ Chemical Shifts of Busulfan (in $\mathrm{CDCl}_{3}$ ), -Cyclodextrin (in $\mathrm{D}_{2} \mathrm{O}$ ), and Busulfan--Cyclodextrin 1:1 and 1:2 Compounds (in $\mathrm{D}_{2} \mathrm{O}$ )

\begin{tabular}{|c|c|c|c|c|c|}
\hline & \multirow[b]{2}{*}{ Free } & \multicolumn{2}{|c|}{ (ppm) } & & \\
\hline & & $1: 1$ & $1: 2$ & & \\
\hline \multicolumn{6}{|c|}{ Busulfan } \\
\hline $\mathrm{H}$ & 4.295 & - & - & $-\mathrm{OCH}_{2}$ & Triplet \\
\hline $\mathrm{H}$ & 3.048 & 2.807 & 2.809 & $-\mathrm{CH}_{3}$ & Singlet \\
\hline \multirow[t]{2}{*}{$\mathrm{H}$} & 1.922 & 1.910 & 1.885 & $-\mathrm{CH}_{2} \mathrm{CH}_{2}$ & Multiplet \\
\hline & & & & $1: 1$ & $1: 2$ \\
\hline \multicolumn{6}{|c|}{-Cyclodextrin } \\
\hline $\mathrm{H}_{1}$ & 5.060 & 5.059 & 5.062 & -0.001 & 0.002 \\
\hline $\mathrm{H}_{2}$ & 3.585 & 3.590 & 3.590 & 0.005 & 0.005 \\
\hline $\mathrm{H}_{3}$ & 3.920 & 3.915 & 3.919 & -0.005 & -0.001 \\
\hline $\mathrm{H}_{4}$ & 3.562 & 3.566 & 3.566 & 0.004 & 0.004 \\
\hline $\mathrm{H}_{5}$ & 3.794 & 3.779 & 3.791 & -0.015 & -0.003 \\
\hline $\mathrm{H}_{6}$ & 3.823 & 3.804 & 3.822 & -0.019 & -0.001 \\
\hline
\end{tabular}

refined atomic multipole parameters and net charges are used to generate the electrostatic potential of busulfan emphasizing the polar character of the terminal methylsulfonate groups. This latter property governs the arrangement of molecules in the solid state and is likely responsible for the strong crystallization of busulfan. In this study, we suggest overcoming this crystallization obstacle for liquid formulations into nontoxic solvents by trying to prepare inclusion complexes of busulfan and cyclodextrins. Powder diffraction and ${ }^{1} \mathrm{H}-$ NMR analyses show that native -cyclodextrins can associate with busulfan in the coprecipitation process described in this paper.

\section{ACKNOWLEDMENTS}

The financial support of the CNRS, Universite' de Paris XI, Ecole Centrale Paris, and Universite' Cadi Ayyad is gratefully acknowledged. The authors would like to thank Dr G. Lebas of Laboratoire Physico-Chimie, Pharmacotechnie, Biopharmacie, for her advice and help in the preparation of busulfan-cyclodextrin systems and Pr. A. Marsura from UMR CNRS 7565-UHP, GEVSM, Faculte' de Pharmacie, Nancy, France, for his help in recording the ${ }^{1} \mathrm{H}-\mathrm{NMR}$ spectra.

\section{REFERENCES}

1. D. A. G. Galton. Myleran in chronic myeloid leukemia: results oftreatment. Lancet 1:208-213 (1953).

2. L. B. Grochow, R. J. Jones, R. B. Brundrett, H. G. Braine, T. L.Chen, R. Saral, G. W. Santos, and O. M. Colvin. Pharmacokinetics of busulfan: correlation with veno-occlusive disease in patients undergoing bone marrow transplantation. Cancer Chemother. Pharmacol. 25:55-61 (1989).

3. G. Vassal, S. Koscielny, D. Challine, D. Valteau-Couanet, I. Boland, A. Deroussent, J. Lemerle, A. Gouyette, and O. Hartmann. Busulfan disposition and hepatic veno-occlusive disease in children undergoing bone marrow transplantation. Cancer Chemother. Pharmacol. 37:247-253 (1996).

4. F. Baron, M. Deprez, and Y. Beguin. The veno-occlusive diseaseof the liver. Haematologica 82:718-725 (1997).

5. E. Olavarria, M. Hassan, A. Eades, C. Nilsson, A. Timms, J.Matthews, C. Craddock, E. Kanfer, J. Apperley, and J. Goldman. A phase I/II study of multiple-dose intravenous busulfan as myeloablation prior to stem cell transplantation. Leukemia 14:1954- 1959 (2000).

6. R. Mackenna, S. Neidle, R. Kuroda, and B. W. Fox. Structures ofthree DNA cross-linking agents, ethane-1,2-di(methylsulfonate), propane-1,3di(methylsulfonate) and n-butane-1,4-di(methylsulfonate). Acta Crystallogr. C45:311-314 (1989).

7. R. F. W. Bader. Atoms in Molecules: A Quantum Theory. Clarendon Press, Oxford, 1990.

8. K. H. Frömming and J. Szejtli (eds). Cyclodextrins in Pharmacy. Topics in Inclusion Science, Vol. 5, Kluwer Academic Publishers, Dordrecht; Boston., 1994.

9. J. Szejtli. Introduction and general overview of cyclodextrinchemistry. Chem. Rev. 98:1743-1753 (1998).

10. J. Bouligand. De'veloppement de nanosphères furtives de busulfan. DEA Report. Universite' Paris V. (2001).

11. Siemens (BRUKER-AXS) Analytical X-ray Instruments Inc.SAINT (6.36A) and SADABS (2.05). Data Collection and Processing Software for the SMART System (5.054). Siemens, Madison, WI, 1998.

12. R. H. Blessing. Outlier treatment in data merging. J. Appl. Crystallogr. 30:421-426 (1997).

13. J. Rodriguez-Carvajal. Recent advances in magnetic structure determination by neutron powder diffraction. Physica B. 192:55-69 (1993).

14. G. M. Sheldrick. SHELXL97 and SHELXS97: Program for therefinement of crystal structures. University of Göettingen, Germany. (1997).

15. L. J. Farrugia. WINGX suite for small-molecule single-crystalcrystallography. J. Appl. Crystallogr. 32:837-838 (1999).

16. N. K. Hansen and P. Coppens. Testing aspherical atom refinements on small-molecule data sets. Acta Crystallogr. A34:909-921 (1978).

17. E. Clementi and C. Roetti. Atomic data and nuclear data tables,Academic Press, New York 14:177-178 (1974).

18. E. Clementi and D. L. Raimondi. Atomic screening constants forSCF functions. J. Chem. Phys. 38:2686-2689 (1963).

19. P. Coppens, T. N. Guru, P. Leung, E. D. Stevens, P. Becker, andY. W. Yang. Net atomic charges and molecular dipole moments from spherical-atom $\mathrm{X}$-ray refinements, and the relation between atomic charge and shape. Acta Crystallogr. A35:63-72 (1979).

20. M. N. Burnett and C. K. Johnson. ORTEP-III report ORNL6895. Oak Ridge International Laboratory, Tennessee. (1996). 
21. N. E. Ghermani, N. Bouhmaida, and C. Lecomte. ELECTROS,STATDENS, FIELD+: Computer programs to calculate electrostatic properties from high resolution X-ray diffraction. Internal report UMR CNRS 7036, Universite' Henri Poincare', Nancy 1, France; UMR CNRS 8612, Universite' Paris XI, France and Universite' Cadi Ayyad, Morocco. (1992-2003).

22. M. Souhassou. Atomic Properties from Experimental Electron Densities: Program Newprop-Int, $19^{\text {th }}$ European Crystallographic Meeting, Nancy, France, August 25-31 2000, Abstract N S2-m2p2, P. 195 (also LCM3B Internal Report, Universite' Henri Poincare', Nancy 1, France).

23. Y. A. Abramov. On the possibility of kinetic energy densityevaluation from the experimental electron-density distribution. Acta Crystallogr. A53:264272 (1997).

24. N. Bouhmaida, N. E. Ghermani, C. Lecomte, and A. Thalal.Molecular fragment electric moments derived from the fit of the experimental electrostatic potential. Application to the water molecule. Acta Crystallogr. A55:729-738 (1999).

25. F. H. Allen. The Cambridge Structural Database: a quarter of amillion crystal structures and rising. Acta Crystallogr. B58:380-388 (2002).

26. D. Cruickshank and M. Eisenstein. The role of d functions inab-initio calculations. Part 1. The deformation densities of $\mathrm{H}_{3} \mathrm{NSO}_{3}$ and $\mathrm{SO}_{3}{ }^{-} . J . M o l$. Struct. 130:143-156 (1985).

27. B. Dittrich, T. Koritsánszky, M. Grosche, W. Scherer, R. Flaig, A. Wagner, H. G. Krane, H. Kessler, C. Riemer, A. M. M. Schreurs, and P. Luger. Reproducability and transferability of topological properties; experimental charge density of the hexapeptide cyclo(D,L-Pro)2-(L-Ala)4 monohydrate. Acta Crystallogr. B58:721- 727 (2002).

28. I. Rozas and D. F. Weaver. Ab-initio study of the methylsulfonate and phenylsulfonate anions. J. Chem. Soc. Perkin Trans. 2 3:461-466 (1996).

29. A. Abramov, A. V. Volkov, and P. Coppens. On the evaluationof molecular dipole moments from multipole refinement of X-ray diffraction data. Chem. Phys. Lett. 311:81-86 (1999).

30. D. Lide (ed). Handbook of Chemistry and Physics, 77th ed. CRC, New York. (1996).

31. T. Steiner and G. Koellner. Crystalline -cyclodextrin hydrate at various humidities: fast, continuous, and reversible dehydration studied by X-ray diffraction. J. Am. Chem. Soc. 116(12):5122-5128 (1994). 